\title{
Measuring social well-being in Africa: An exploratory structural equation modelling study
}

\begin{tabular}{|c|c|}
\hline \multicolumn{2}{|c|}{$\begin{array}{l}\text { Authors: } \\
\text { Itumeleng P. Khumalo } \\
\text { Ufuoma P. Ejoke }^{1} \text { (D) } \\
\text { Kwaku Oppong Asante }^{1,2} \text { (D) } \\
\text { Janvier Rugira }{ }^{3} \text { (D) }\end{array}$} \\
\hline \multicolumn{2}{|c|}{$\begin{array}{l}\text { Affiliations: } \\
{ }^{1} \text { Department of Psychology, } \\
\text { Faculty of Humanities, } \\
\text { University of the Free State, } \\
\text { Bloemfontein, South Africa }\end{array}$} \\
\hline \multicolumn{2}{|c|}{$\begin{array}{l}\text { Department of Psychology, } \\
\text { University of Ghana, Accra, } \\
\text { Ghana }\end{array}$} \\
\hline \multicolumn{2}{|c|}{$\begin{array}{l}{ }^{3} \text { Psychosocial Wellbeing } \\
\text { Section, United Nations High } \\
\text { Commission for Refugees, } \\
\text { Pretoria, South Africa }\end{array}$} \\
\hline \multicolumn{2}{|c|}{$\begin{array}{l}\text { Corresponding author: } \\
\text { Itumeleng Khumalo, } \\
\text { khumaloip@ufs.ac.za }\end{array}$} \\
\hline \multicolumn{2}{|c|}{$\begin{array}{l}\text { Dates: } \\
\text { Received: } 01 \text { Oct. } 2020 \\
\text { Accepted: } 19 \text { May } 2021 \\
\text { Published: } 28 \text { June } 2021\end{array}$} \\
\hline \multicolumn{2}{|c|}{$\begin{array}{l}\text { How to cite this article: } \\
\text { Khumalo, I.P., Ejoke, U.P., } \\
\text { Oppong Asante, K., \& Rugira, } \\
\text { J. (2021). Measuring social } \\
\text { well-being in Africa: An } \\
\text { exploratory structural } \\
\text { equation modelling study. } \\
\text { African Journal of } \\
\text { Psychological Assessment, } \\
\text { 3(0), a37. https://doi. } \\
\text { org/10.4102/ajopa.v3i0.37 }\end{array}$} \\
\hline \multicolumn{2}{|c|}{$\begin{array}{l}\text { Copyright: } \\
\text { (C) 2021. The Authors. } \\
\text { Licensee: AOSIS. This work } \\
\text { is licensed under the } \\
\text { Creative Commons } \\
\text { Attribution License. }\end{array}$} \\
\hline \multicolumn{2}{|l|}{ Read online: } \\
\hline 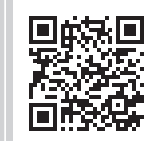 & $\begin{array}{l}\text { Scan this QR } \\
\text { code with your } \\
\text { smart phone or } \\
\text { mobile device } \\
\text { to read online. }\end{array}$ \\
\hline
\end{tabular}

Authors:

Ufuoma P. Ejoke ${ }^{1}$ (D)

Kwaku Oppong Asante ${ }^{1,2}$ (D)

Faculty of Humanities,

University of the Free State,

${ }^{2}$ Department of Psychology, University of Ghana, Accra,

${ }^{3}$ Psychosocial Wellbeing

Section, United Nations High

Commission for Refugees,

Corresponding author:

Itumeleng Khumalo,

Dates:

Received: 01 Oct. 2020

Accepted: 19 May 2021

How to cite this article:

Khumalo, I.P., Ejoke, U.P. , A Rugira, well-being in Africa: An exploratory structural African Journal of Psychological Assessment 3(0), a37. https://doi.

Copyright:

(C) 2021. The Authors. Licensee: AOSIS. This work is licensed under the Creative Commons Attribution License.

mobile device
to read online
The study investigated the factor structure of the 15-item social well-being scale in an African context. Social well-being is categorised into five dimensions: social integration, social contribution, social coherence, social actualisation and social acceptance. Data were collected from 402 participants in South Africa (50\% male, average age of 21 years). Confirmatory factor analysis (CFA) and exploratory structural equation modelling (ESEM) were conducted in Mplus (version 8.1), on the 15-item measure. Results showed advantages of ESEM's flexibility, through which an unstable emic four factor solution emerged. For such complex multidimensional psychological constructs measured in novel contexts, ESEM is best suited for exploring factorial validity. Although the present study's findings should have implication for theory, future studies should further explore social well-being measurement using the long- and short-form instruments in diverse African samples.

Keywords: Africa; ESEM; factorial validity; measurement; social well-being.

\section{Introduction}

The understanding of well-being as something with only an intrapersonal location misses the reality that people are both private and public beings whose lives are socially and communally embedded (Keyes, 1998; Kpanake, 2018; Prilleltensky, 2005). White (2010) described well-being as social process with material, relational and subjective dimensions and emphasised the centrality of relatedness. Not only do sense of belonging, community and relationships constitute wellbeing (Ryff, 1989; White, 2010) but also feature prominently in what gives meaning to life (Wissing, 2014). According to Helliwell, Barrington-Leigh, Harris and Huang (2010), people make more positive evaluation of their lives when they live in societies where they themselves and others have people to rely on. Well-being is located in the social and cultural domains (White, 2010).

The social and community embeddedness of people is an integral characteristic of the African socio-cultural orientation in which the social good takes precedence over separate personhood (Kpanake, 2018; Molefe, 2017; Nyamnjoh, 2017, 2019; Wissing \& Temane, 2013). It therefore makes sense that those interested in the study of well-being in an African context should take into account the social, relational and communal dimensions of well-being (see Chilisa \& Tsheko, 2014; Mertens, 2016; Wilson, Wissing, \& Schutte, 2019) and its measurement. From an African socio-cultural perspective, the nature of being is inherently relational (Chilisa, Major, \& KhuduPetersen, 2017). Social well-being is important because it captures a socially oriented conceptualisation of well-being (Patri, Albanesi, \& Pietrantoni, 2016).

Given the significance of sense of community and relationships (Neto \& Marujo, 2013; Molefe, 2017), the present study explored the factor structure of the five dimensional model social wellbeing of Keyes (1998). Social well-being captures how well an individual functions in their social life as a member of the greater community (Keyes, 1998). Keyes (1998, p.122) defined social wellbeing as 'the appraisal of one's circumstances and functioning in society', and proposed a five factor structure consisting of social integration, social acceptance, social contribution, social actualisation and social coherence. Social integration refers to the quality of an individual's perception of belonging and acceptance in the society (Keyes, 1998). It is therefore the extent to which people feel they have things in common with members of their environment (Keyes, 1998; Keyes \& Shapiro, 2004). Social acceptance captures the meaning that individuals construct of their society as one that is accepting, characterised by trust, social comfort and the belief that people are kind and industrious. Social contribution is the evaluation of one's social worth through their perceived ability to give to others in the community (Keyes, 1998). It is intertwined with the evaluation of being an important member of the society and having the ability to contribute. Social 
actualisation reflects the judgement that society has potential and it is growing and developing in a right trajectory. Social coherence captures the understanding of the social world as being making sense, organised, functioning well and predictable (Keyes, 1998, 2006; Keyes \& Shapiro, 2004).

In the original measurement development and validation studies amongst adults in the United States of America, Keyes (1998) confirmed the theoretically intended five factor model using the longer form and shorter form. The measure demonstrated good convergent and discriminant validity as demonstrated by theoretically expected relationships with generativity, health of neighbourhood, dysphoric symptoms and subjective physical health (Keyes, 1998). Except for social acceptance, which had a lower reliability index, Keyes (1998) found the other four subscales had good internal consistency. Age was also found to be an influential factor in social wellbeing measurement. Except for social coherence, the other four dimensions were found to increase with age, albeit slower each year (Keyes, 1998). According to Keyes (1998), the observation that social coherence is higher amongst younger people can be attributed to their experience of the world reflecting their popular culture.

Outside of the many studies concerned with the mental health continuum (e.g. Joshanloo, Bobowik, \& Basabe, 2016; Joshanloo, Wissing, Khumalo, \& Lamers, 2013; Lamers, Westerhof, Bohlmeijer, Ten Klooster, \& Keyes, 2011), only a few studies concerned specifically with the measurement of social well-being could be located (e.g. De Jager, Coetzee, \& Visser, 2018; Shayeghian, Amiri, Vahedi-Notash, Karimi, \& Azizi, 2019). The use of the 15-item measure is an improvement on the five-item subscale of the mental health continuum short form (MHC-SF) because each of the dimensions is measured using three items. Shayeghian et al. (2019) applied exploratory factor analysis (EFA) and confirmatory factor analysis (CFA) to validate the Iranian version of the 15 -item social well-being measure, which they found that, albeit with minor modifications, retained the intended factor structure. Their minor modifications included two pairs of covariance, in social integration and social coherence and the removal of the item 'People who do a favour expect nothing in return' of the social acceptance dimension (Shayeghian et al., 2019). In Portugal, CFA on the 33-item long-format Portuguese version measure yielded the theoretically intended five-factor structure, with good concurrent validity (Lages, Magalhães, Antunes, \& Ferreira, 2018).

A South African study utilising the 15-item short-form version found an emic factor structure comprising three dimensions amongst a sample of employees in a motor manufacturing sector (De Jager et al., 2008). Notwithstanding that De Jager et al. (2008) could not replicate Keyes' (1998) theoretically intended model, their interpretation of the factor solution was contextually meaningful and useful for our exploration. They named their three emergent factors: social predictability and growth, social trust and social value and belonging, leading them to express a careful observation that 'social well-being in South Africa might be operationalised differently' (De Jager et al., 2008, p.57). None of these studies used exploratory structural equation modelling (ESEM).

It is evident that the majority of previous studies relied on the use of CFA. The limitations of CFA, and the advantages of ESEM, are acknowledged by a number of scholars and methodologists (e.g. Asparouhov \& Muthen, 2009; Marsh, Morin, Parker, \& Kaur, 2014; Perry, Nicholls, Clough, \& Crust, 2015). According to Marsh et al. (2014), the multidimensional structures of many psychological scales cannot be sufficiently represented using simple CFA models. In fact, this practice results in poor model fit and overestimation of factor correlations (Marsh et al., 2014). Recent studies have supported the use of ESEM as its flexibility allows for better model fit and less inflated interfactors correlations (Marsh et al., 2014). The flexibility of ESEM is inherent in the sense that all items are specified to load on all the factors. This strategy allows cross-loadings, which tend to produce more realistically estimated factor correlations and better fit (Marsh et al., 2014). Examples of the use of ESEM in studying the factorial validity of multidimensional measures in positive psychology include Benitez-Borrego, Guàrdia-Olmos and Urzúa-Morales (2014), Joshanloo (2016a, 2016b, 2016c) and Joshanloo et al. (2016). In all of these studies, ESEM was found to be superior to CFA. According to Marsh et al. (2014), ESEM incorporates CFA and EFA, whilst EFA is considered to be suboptimal to CFA because of its open-ended exploratory nature.

The present study expands the research conducted by De Jager et al. (2008), amongst others, through applying CFA and ESEM to investigate the factor structure of the social wellbeing measure in an African sample. As indicated by Lages et al. (2018, p.16) 'a proper understanding of mental health derives from the existence of valid and reliable measurement instruments, theoretically driven and adapted to their application contexts'. In line with this need for a contribution, whether the factor structure of Keyes social well-being holds true amongst African sample, needs to be examined. Thus, we needed to respond to the question of whether the social well-being indicators, namely social integration, social contribution, social coherence, social actualisation and social acceptance, as operationalised in Keyes (1998) model, should be used for assessment of social well-being in Africa.

\section{Methods Participants}

Quantitative data were collected using a cross-sectional survey in which 402 students in South Africa participated. Data collection took place in 2015 at a university of technology located in the Gauteng province of South Africa. The sample consisted of 199 male (49.5\%) and 191 female (47.5\%) (12 people did not indicate their gender) students between the ages of 18 and 34 years, with an average age of 21.74 (standard deviation $[$ s.d.] $=2.34$ ) years. 


\section{Measuring instrument}

\section{Social Well-being Scale Short-Form}

The Social Well-being Scale Short-Form (SWS-SF) (Keyes, 1998) is a 15-item scale designed to measure social well-being based on the five dimensions indicating how individuals appraise circumstances and functioning in society. It is scored on a 6-point Likert scale ranging from strongly disagree (1) to strongly agree (7). The five dimensions, social integration, social contribution, social coherence, social actualisation and social acceptance are each measured using three items. In the original study, Keyes (1998) found the subscales, except for social acceptance ( 0.41$)$ to be reliable, as shown by Cronbach's alpha coefficients ranging between 0.64 and 0.73 . Using CFA in Iran, Shayeghian et al. (2019) found modest reliability indices. In Portugal, Lages et al. (2018) found, the long version to be reliable. In South Africa, De Jager et al.'s (2008) three factor model also produced internally coherent dimensions: social predictability and growth $(\alpha=0.62)$, social trust ( $\alpha=0.69)$, social value and belonging $(\alpha=0.74)$.

\section{Procedure and ethical considerations}

Data in the present study were collected as part of a project named Hope, motivation and social well-being: Exploring eudaimonic well-being amongst youth, (approved by the NorthWest University Research Ethics Regulatory Committee [reference number: NWU-00138-14-A8] and Vaal University of Technology Research and Innovation Ethics Committee [reference number: 20140425-1ms]). After the recruitment and consent process, the completion of questionnaires commenced under the supervision of research assistants and student tutors. Guidelines from the Helsinki Declaration (World Health Organization [WHO], 2001) and the South African Department of Health $(2014,2015)$, were followed. The written informed consent entailed all the necessary information through which the participant would know about the study, details of its procedures, risks and potential benefits and their ethically entrenched rights such as confidentiality, voluntary participation and withdrawal.

\section{Data analysis}

The present study investigated the model fit of the SWS-SF (15 items) using CFA and ESEM in Mplus (Muthén \& Muthén, 1998-2017). We used robust maximum likelihood (MLR) estimation, with oblique geomin rotation. The fivefactor model was tested first with CFA and second with ESEM. Their model fits were tested using chi-square $\left(\chi^{2}\right)$, root mean square error of approximation (RMSEA), standardised root mean square residual (SRMR), comparative fit index (CFI), akaike information criterion (AIC) and Bayesian information criterion (BIC) (Geiser, 2013). For good fit, the following criteria were used: smaller and insignificant $\chi^{2}$; RMSEA and SRMR of less than 0.06; CFI of more than 0.95; Tucker-Lewis index (TLI) of more than 0.95; smaller AIC and smaller BIC (Byrne, 2012; Geiser, 2013; Hu \& Bentler, 1999; Wang \& Wang, 2012).

\section{Results}

The CFA five factor model in which each item loaded only on its one intended factor (Figure 1), yielded poor fit, $\chi^{2}(80)=$ 305.149, $p<0.000$; CFI $=0.706$; RMSEA $=0.091, p<0.000$ [0.080 0.102]. The ESEM model fits the data better, $\chi^{2}(40)=$ 69.195, $p=0.002 ; \mathrm{CFI}=0.950 ; \mathrm{RMSEA}=0.047, p=0.588[0.028$ 0.065]. Model fit indices are displayed in Table 1.

The standardised factor loadings for the CFA and ESEM models, based on the five factor solution are reported (Table 2). In the CFA model, except for the social contribution subscale, all the others have only two of the three items with factor loadings above 0.30 . This unstable internal consistency renders not only the five dimensional structure proposed by Keyes (1998) untenable but also makes for an ill-fitting, highly restrictive CFA model.

The following items had non-salient loadings on any of the factors: 'I don't feel I belong to anything I'd call a community' (item 1 of social Integration), 'People do not care about other people's problems' (item 5 of social acceptance) and 'I find it easy to predict what will happen next in society' (item 15 of social coherence). With one item excluded, social integration is indicated by two items which speak to the community being a source of safety. Social coherence is indicated by three items in total: two from social acceptance and one from social actualisation. Two items from social coherence and two items from social actualisation had salient loadings on social acceptance. Lastly, the three items of social contribution straddle between social contribution and social actualisation. Item 9 'I have nothing important to contribute to society' cross-

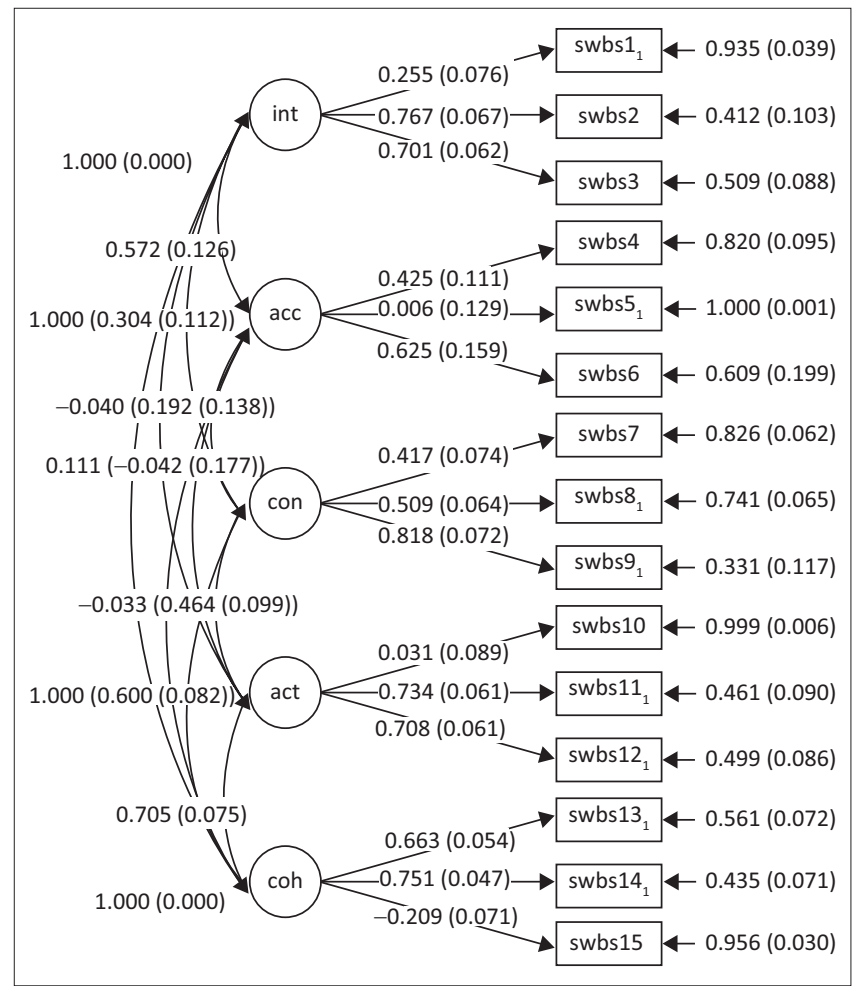

FIGURE 1: Confirmatory factor analysis model. 
TABLE 1: Model fit indices.

\begin{tabular}{|c|c|c|c|c|c|c|c|c|c|c|c|}
\hline \multirow[t]{3}{*}{ Model } & \multicolumn{11}{|c|}{ Model fit indices } \\
\hline & \multirow[t]{2}{*}{$\chi^{2}$} & \multirow[t]{2}{*}{ df } & \multirow[t]{2}{*}{$P$} & \multirow[t]{2}{*}{ AIC } & \multirow[t]{2}{*}{ BIC } & \multirow[t]{2}{*}{ RMSEA } & \multirow[t]{2}{*}{$P$} & \multicolumn{2}{|c|}{ RMSEA $90 \% \mathrm{Cl}$} & \multirow[t]{2}{*}{ CFI } & \multirow[t]{2}{*}{ SRMR } \\
\hline & & & & & & & & Lower & Upper & & \\
\hline CFA & 305.149 & 80 & $<0.000$ & 18629 & 18839 & 0.091 & $<0.000$ & 0.080 & 0.102 & 0.706 & 0.107 \\
\hline ESEM & 69.195 & 40 & 0.002 & 18421 & 18785 & 0.047 & 0.588 & 0.028 & 0.065 & 0.961 & 0.023 \\
\hline \multicolumn{12}{|c|}{$\begin{array}{l}\chi^{2} \text {, Chi-square; df, degrees of freedom; } P \text {, probability estimate; AIC, Akaike information criterion; BIC, Bayesian information criterion; CFI, comparative fit index; Cl, confidence interval; RMSEA, roo } \\
\text { mean square error of approximation; SRMR, standard root mean square residual; CFA, confirmatory factor analysis; ESEM, exploratory structural equation modelling. }\end{array}$} \\
\hline \multirow{2}{*}{\multicolumn{2}{|c|}{ Latent and indicator variables }} & & & \multicolumn{8}{|c|}{ Standardised factor loadings } \\
\hline & & & & Integ & & Acceptance & Contribution & & Actualisation & Coherence & CFA \\
\hline \multicolumn{12}{|c|}{ Social integration } \\
\hline 1. I do & long to an & roulc & ommunity & 0.115 & & $0.230(0.135)$ & $0.200(0.261)$ & & $0.225(0.207)$ & $-0.012(0.076)$ & 0.255 \\
\hline 2. Ife & her people & $\mathrm{mm}$ & & 0.701 & 77) $\dagger$ & $0.014(0.066)$ & $0.067(0.137)$ & & $0.013(0.058)$ & $0.006(0.155)$ & $0.767 \dagger$ \\
\hline 3. My & $s$ a source & & & 0.694 & 02) $\dagger$ & $-0.009(0.072)$ & $-0.029(0.079)$ & & $0.003(0.053)$ & $0.189(0.236)$ & $0.701 \dagger$ \\
\hline 4. Peo & favour ex & ing & & 0.091 & 52) & $-0.073(0.113)$ & $-0.007(0.102)$ & & $0.063(0.102)$ & $0.373(0.121)$ & $0.425 \dagger$ \\
\hline 5. Peo & re about 0 & ple's & & 0.012 & 06) & $0.230(0.114)$ & $-0.064(0.082)$ & & $0.149(0.122)$ & $-0.012(0.108)$ & 0.006 \\
\hline 6. I be & ople are ki & & & 0.073 & 49) & $-0.006(0.076)$ & $0.235(0.206)$ & & $0.082(0.124)$ & $0.424(0.262) \dagger$ & $0.625 \dagger$ \\
\hline \multicolumn{12}{|c|}{ Social contribution } \\
\hline 7. I ha & g valuable & the & & 0.008 & 33) & $-0.041(0.059)$ & $0.859(0.577) \dagger$ & & $0.033(0.096)$ & $0.075(0.324)$ & $0.417 \dagger$ \\
\hline $\begin{array}{l}\text { 8. My } \\
\text { my }\end{array}$ & $s$ do not $p$ & nyth & thwhile for & 0.000 & 23) & $-0.001(0.085)$ & $-0.005(0.040)$ & & $0.818(0.179) \dagger$ & $0.036(0.100)$ & $0.509 \dagger$ \\
\hline 9. I ha & nportant t & & & -0.024 & 32) & $0.190(0.163)$ & $0.407(0.402) \dagger$ & & $0.374(0.245) \dagger$ & $-0.059(0.167)$ & $0.818 \dagger$ \\
\hline \multicolumn{12}{|c|}{ Social actualisation } \\
\hline 10. Th & coming $a$ & & one & 0.019 & 37) & $0.146(0.145)$ & $0.061(0.116)$ & & $0.112(0.175)$ & $0.553(0.235) \dagger$ & 0.031 \\
\hline 11. So & pped maki & & & -0.117 & 74) & $0.803(0.176) \dagger$ & $-0.029(0.079)$ & & $0.139(0.321)$ & $0.044(0.101)$ & $0.734 \dagger$ \\
\hline 12. So & nproving $\mathrm{f}$ & like & & -0.031 & 20) & $0.623(0.165) \dagger$ & $-0.037(0.087)$ & & $0.182(0.300)$ & $0.190(0.166)$ & $0.708 \dagger$ \\
\hline \multicolumn{12}{|c|}{ Social coherence } \\
\hline 13. Th & o complex & & & 0.159 & 86) & $0.513(0.139) \dagger$ & $0.013(0.349)$ & & $0.056(0.077)$ & $-0.150(0.319)$ & $0.663 \dagger$ \\
\hline 14. I & sense of $w$ & ng o & world & 0.147 & 72) & $0.576(0.162) \dagger$ & $0.127(0.326)$ & & $0.012(0.040)$ & $-0.222(0.324)$ & $0.751 \dagger$ \\
\hline
\end{tabular}

CFA, confirmatory factor analysis.

$\dagger$, standardised factor loadings showing significant loading of an item on the factor/dimension.

TABLE 3: Inter-factor correlations in confirmatory factor analysis.

\begin{tabular}{lccccc}
\hline Variables & Integration & \multicolumn{1}{c}{ Acceptance } & Contribution Actualisation & Coherence \\
\hline Integration & 1 & - & - & - & - \\
Acceptance & 0.572 & 1 & - & - & - \\
Contribution & 0.304 & 0.192 & 1 & - & - \\
Actualisation & -0.040 & -0.042 & 0.464 & 1 & - \\
Coherence & 0.111 & -0.033 & 0.600 & 0.705 & 1 \\
\hline
\end{tabular}

TABLE 4: Inter-factor correlations in exploratory structural equation modelling. Variables Integration Acceptance Contribution Actualisation Coherence Integration 1

\begin{tabular}{lccccc} 
Acceptance & -0.030 & 1 & - & - & - \\
Contribution & 0.466 & 0.153 & 1 & - & - \\
Actualisation & 0.097 & 0.468 & 0.152 & 1 & - \\
Coherence & 0.311 & -0.126 & 0.056 & -0.148 & 1 \\
\hline
\end{tabular}

loads on two dimensions, whilst item 7 'I have something valuable to give to the world' was retained in social contribution and item 8 'My daily activities do not produce anything worthwhile for my community' loads on social actualisation by itself.

The inter-factor correlations for the ill-fitting CFA model (Table 3), range between -0.33 and 0.705 . The inter-factor correlations from the ESEM model, which range between -0.148 and 0.468 are shown (Table 4). A clear difference between the two sets of correlations is the moderate range in the ESEM model as compared with some of the extreme correlation coefficients seen in the CFA model. However, the prevalence of non-target factor loadings of the indicator items in this ESEM model makes the hypothetical five factor structure untenable.

\section{Discussion}

The findings of this study show a deviation from the theoretically intended five-factor model proposed by Keyes (1998), with CFA yielding poor fit and ESEM being characterised by a number of non-target loadings. An emic four factor solution from the ESEM model, albeit with a degree of instability, was interpretable. The following four dimensions are observed: community as a source of safety (two items), the world as understandable (four items), the world as generous and kind (three items) and ability to contribute (two items). With four items excluded, this structure is made up of only 11 items. Two of the factors consist of only two items, making them minor factors.

The three items with no salient loadings on any of the factors, even with the ESEM option of flexible cross-loading were items 1 'I don't feel I belong to anything I'd call a community'; item 5 'People do not care about other people's problems' and item 15 'I find it easy to predict 
what will happen next in society'. Items 1 and 5 may suggest that there is a negative wording factor or that the two items hold contextual interpretation, which offers the reasons for exclusion. In the absence of a negative wording factor, the latter is more plausible. It is possible, as opined by Ryff and Singer (1998) that the questions of not belonging to a community and that people's problems would not be cared about are incomprehensible in an African socio-cultural context. Two possible reasons may explain why item 15 does not resonate with the respondents in this study. The first has to do with the strong shouldering of responsibility to predict and the second points to the item's insistence on future-orientation and assumption of certainty of knowing what will happen next. The view that future-orientation does not enjoy salience in many African societies was made popular by amongst others Mbiti (1991). The high value of needing to predict what will happen in society makes an assumption of the society's tolerance for ambiguity (see Hofstede, 2011). Cultures, which are comfortable with unstructured situations, set and follow less rules and tend to live in the moment and are more tolerant to different opinions and are open to different experiences (Hofstede, 2011). Ryff and Singer's (1998) conception of practical wisdom and improvisation valued in an African socio-cultural context may offer a plausible explanation.

\section{Community as a source of safety}

Community as a source of safety dimension is constituted by content from the salient loading of two items, namely item 2: 'I feel close to other people in my community' and item 3: 'My community is a source of comfort', which had been intended to be indicators of social integration. In a study by De Jager et al. (2008), these two items, together with the two which are indicative of the ideas that the world is becoming a better place and that people are kind, were thought to represent social trust.

\section{The world as understandable}

The world as understandable is made up of four items representing item 11: 'Society has stopped making progress'; item 12: 'Society isn't improving for people like $\mathrm{me}^{\prime}$; item 13: 'The world is too complex for me'; item 14: 'I cannot make sense of what's going on in the world'. The first two items were intended as indicators of social actualisation and the other two for social coherence. This dimension is reminiscent of the comprehensibility dimension of Antonovsky's (1993) sense of coherence model. It refers to the experience of the world as being ordered, constant, structured and clear. The opposite end of this spectrum, as expressed by Antonovsky (1993), would be if the world is characterised by chaos, disorder, randomness and inexplicability.

\section{The world as generous and kind}

The world as generous and kind dimension is indicated by three items, which are item 4: 'People who do a favour expect nothing in return', item 6: 'I believe that people are kind' and item 10: 'The world is becoming a better place for everyone'. This three item factor is reminiscent of the (individual) strength of kindness (see Park, Peterson, \& Seligman, 2004), which is characterised by generosity, nurturance and care, when expressed at an individual level.

\section{Ability to contribute}

This factor is indicated by item 7: 'I have something valuable to give to the world' and item 9: 'I have nothing important to contribute to society'. Missing from this social contribution factor is item 8: 'My daily activities do not produce anything worthwhile for my community', which loaded on its own unique factor by itself. In Keyes' terms, it seems that one's sense of meaningful membership of a society hinges on their belief that they have something of value to offer. In an African context, the magnitude of this generosity is never in question or under judgement. As Ryff and Singer (1998, p.5) observed, 'Africans have no conception of the person apart from the community'.

\section{Limitations and recommendations}

The present study was applied on a single sample. A multisample study using a series of different factor analytical approaches would help in providing greater evidence of consistency of these seemingly novel findings. Even when it may appear from this study 'that ESEM is a more appropriate method for examining the factor structure of well-being scales' (Joshanloo et al., 2016, p.107), the inconclusive findings encourage future studies. We also used the short-form version of the scale. It is possible that a long-form version may produce more information about the factorial stability of the social well-being model. Lastly, qualitative studies, which use more inductive forms of exploration of a phenomenon, would help to define and describe social wellbeing from a laypeople's perspective (see Delle Fave et al., 2016; Mozaffari, Peyrovi, \& Nayeri, 2015; Wilson Fadiji, Meiring, \& Wissing, 2019).

\section{Conclusion}

It may be that in addition to the present study, there are at least two more empirical investigations (De Jager et al., 2008; Joshanloo, 2018) whose results attest to the heterogeneity and possible instability of the social well-being dimensions. These findings attest to the complexity of well-being as a socially embedded construct (see White, 2017). Acknowledging that well-being is not only located at a micro-level of individuals but it is also to understand that human lives are shaped by their ecology (Gruner \& Csikszentmihalyi, 2018).

\section{Acknowledgements Competing interests}

The authors declare that they have no financial or personal relationships that may have inappropriately influenced them in writing this article. 


\section{Authors' contributions}

I.P.K., U.P.E., K.O.A., and J.R. all contributed equally to this work.

\section{Funding information}

This research received no specific grant from any funding agency in the public, commercial or not-for-profit sectors.

\section{Data availability}

A data set was generated through a cross-sectional survey conducted amongst students at a university of technology in South Africa.

\section{Disclaimer}

The views and opinions expressed in this article are those of the authors and do not necessarily reflect the official policy or position of any affiliated agency of the authors.

\section{References}

Antonovsky, A. (1993). The structure and properties of the sense of coherence scale. Social Science and Medicine, 36(6), 725-733. https://doi.org/10.1016/02779536(93)90033-Z

Asparouhov, T., \& Muthen, B. (2009). Exploratory structural equation modelling. Structural Equation Modelling: A Multidisciplinary Journal, 16(3), 397-438. https://doi.org/10.1080/10705510903008204

Benitez-Borrego, S., Guàrdia-Olmos, J., \& Urzúa-Morales, A. (2014). Factorial structural analysis of the Spanish version of WHOQOL-BREF: An exploratory structural equation model study. Quality of Life Research, 23(8), 2205-2212. $\mathrm{https}$ ://doi.org/10.1007/s11136-014-0663-2

Byrne, B.M. (2012). Structural equation modeling with mplus: Basic concepts, applications, and programming. New York, NY: Routledge.

Chilisa, B., Major, T.E., \& Khudu-Petersen, K. (2017). Community engagement with a postcolonial, African-based relational paradigm. Qualitative Research, 17(3), 326-339. https://doi.org/10.1177/1468794117696176

Chilisa, B., \& Tsheko, G.N., (2014). Mixed methods in indigenous research: Building relationships for sustainable intervention outcomes. Journal of Mixed Methods
Research, 8(3), 222-233. https://doi.org/10.1177/1558689814527878

De Jager, M., Coetzee, S., \& Visser, D. (2008). Dimensions of social well-being in a motor manufacturing organisation in South Africa. Journal of Psychology in Africa, 18(1), 57-64. https://doi.org/10.1080/14330237.2008.10820171

Delle Fave, A., Brdar, I., Wissing, M.P., Araujo, U., Castro Solano, A., Freire, T., ... SoosaiNathan, L. (2016). Lay definitions of happiness across nations: The primacy of inner harmony and relational connectedness. Frontiers in Psychology, 7(30), 1-23. https://doi.org/10.3389/fpsyg.2016.00030

Geiser, C. (2013). Data Analysis with Mplus. New York, NY: Guilford Press.

Gruner, D.T., \& Csikszentmihalyi, M. (2018). Towards a new measure of societal wellbeing. In N.J.L. Brown, T. Lomas, \& F.J. Eiroa-Orosa (Eds.), The Routledge international handbook of critical positive psychology (pp. 377-391). London: Routledge.

Helliwell, J.F., Barrington-Leigh, C., Harris, A., \& Huang, H. (2010). International evidence on social context of well-being. In E. Diener, J.F. Helliwell, \& D. Kahneman (Eds.), International differences in well-being (pp. 291-327). Oxford University Press.

Hofstede, G. (2011). Dimensionalizing cultures: The Hofstede model in context. Online Readings in Psychology and Culture, 2(1), 1-26. https://doi.org/10.9707/23070919.1014

Hu, L.T., \& Bentler, P.M. (1999). Cutoff criteria for fit indixes in covariance structure analysis: Conventional criteria versus new alternatives. Structural Equation Modeling, 6(1), 1-55. https://doi.org/10.1080/10705519909540118

Joshanloo, M. (2016a). Revisiting the empirical distinction between hedonic and eudaimonic aspects of well-being using exploratory structural equation modelling. Journal of Happiness Studies, 17(5), 2023-2036. https://doi.org/10.1007/s10902015-9683-z

Joshanloo, M. (2016b). A new look at the factor structure of the MHC-FS in Iran and the United States using exploratory structural equation modeling. Journal of Clinical Psychology, 72(7), 701-713. https://doi.org/10.1002/jclp.22287

Joshanloo, M. (2016c). Factor structure of subjective well-being in Iran. Journal of Personality Assessment, 98(4), 435-443. https://doi.org/10.1080/00223891.2015 .1117473

Joshanloo, M., Bobowik, M., \& Basabe, N. (2016). Factor structure of mental wellbeing: Contributions of exploratory structural equation modeling. Personality and Individual Differences, 102, 107-110. https://doi.org/10.1016/j.paid.2016.06.060
Joshanloo, M., Wissing, M.P., Khumalo, I.P., \& Lamers, S.M.A. (2013). Measurement invariance of the Mental Health Continuum-Short Form (MHC-SF) across three cultural groups. Journal of Personality and Individual Differences, 55(7), 755-759. https://doi.org/10.1016/j.paid.2013.06.002

Joshanloo, M. (2018). The structure of the MHC-SF in a large American sample: Contributions of multidimensional scaling, Journal of Mental Health, 29(2), 139-143. https://doi.org/10.1080/09638237.2018.1466044

Keyes, C.L.M., \& Shapiro, A.D. (2004). Social well-being in the United States: A descriptive epidemiology. In O.G. Brim, C.D. Ryff, \& R.C. Kessler (Eds.), How healthy are we?: A national study of well-being at midlife (pp. 350-372). Chicago, IL: The University of Chicago Press.

Keyes, C.L.M. (2006). Mental health in adolescence: Is America's youth flourishing? American Journal of Orthopsychiatry, 76, 395-402. https://doi.org/10.1037/0002 9432.76.3.395

Keyes, C.L.M. (1998). Social well-being. Social Psychology Quarterly, 61(2), 121-140. https://doi.org/10.2307/2787065

Kpanake, L. (2018). Cultural concepts of the person and mental health in Africa. TransculturalPsychiatry,55(2),198-218.https://doi.org/10.1177/1363461517749435

Lages, A., Magalhães, E., Antunes, C., \& Ferreira, C. (2018). Social well-being scales: validity and reliability evidence in the Portuguese context. Psicologia, 32(2) 15-26. https://doi.org/10.17575/rpsicol.v32i2.1334

Lamers, S.A., Westerhof, G.F., Bohlmeijer, E.T., Ten Klooster, P.M., \& Keyes, C.L.M (2011). Evaluating the psychometric properties of the metal health continuum short form (MHC-SF). Journal of Clinical Psychology, 67(1), 99-110. https://doi. org/10.1002/jclp.20741.

Marsh, H.W., Morin, A.J.S., Parker, P.D., \& Kaur, G. (2014). Exploratory structural equation modelling: An integration of the best features of exploratory and confirmatory factor analysis. Annual Review of Clinical Psychology, 10, 85-110. https://doi.org/10.1146/annurev-clinpsy-032813-153700

Mbiti, J.S. (1991). Introduction to African religion (2nd edn.). Oxford: Heinemann.

Mertens, D.M. (2016). Advancing social change in South Africa through transformative research. South African Review of Sociology, 47(1), 5-17. https://doi. org/10.1080/21528586.2015.1131622

Molefe, M. (2017). Critical comments on Afro-communitarianism: The community versus individual. Filosofia Theoretica: Journal of African Philosophy, Culture and Religions, 6(1), 1-22. https://doi.org/10.4314/ft.v6i1.1

Mozaffari, N., Peyrovi, H., \& Nayeri, N.D. (2015). The social well-being of nurses shows a thirst for a holistic support: A qualitative study. International Journal of Qualitative Studies on Health and Well-being, 10(1), 1-8. https://doi.org/10.3402/ qhw.v10.27749

Muthén, L.K., \& Muthén, B.O. (1998-2017). Mplus statistical analysis with latent variables: Users' guide (8th edn.). Los Angeles, CA: Muthén \& Muthén.

Neto, L., \& Marujo, H. (2013). Positive community psychology and positive community development: Research and intervention as transformative-appreciative actions In H. Marujo \& L.M. Neto (Eds.), Building positive nations and communities (pp. 209-230). Dordrecht: Springer.
(n H. Marujo \& L.M. Neto (Eds.

Nyamnjoh, F.B. (2017). Incompleteness: Frontier Africa and the currency of conviviality. Journal of Asian and African Studies, 52(3), 253-270. https://doi. org/10.1177/0021909615580867

Nyamnjoh, F.B. (2019, May 22). Ubuntuism and Africa: Actualised, misappropriated endangered and reappraised [Lecture presentation]. Africa Day Memorial Lecture, University of the Free State, Bloemfontein. Retrieved from https://bit.ly/37x8er6

Park, N., Peterson, C., \& Seligman, M.E.P. (2004). Strengths of character and wellbeing. Journal of Social and Clinical Psychology, 23(5), 603-619. https://doi. org/10.1521/jscp.23.5.603.50748

Patri, G., Albanesi, C., \& Pietrantoni, L. (2016). The reciprocal relationship between sense of community and social well-being: A cross-lagged panel analysis. Socia Indicators Research, 127, 1321-1332. https://doi.org/10.1007/s11205-015-1012-8

Perry, J.L., Nicholls, A.R., Clough, P.J., \& Crust, L. (2015). Assessing model fit: Caveats and recommendations for confirmatory factor analysis and exploratory structural equation modelling. Measurement in Physical Education and Exercise Science, 19(1), 12-21. https://doi.org/10.1080/1091367X.2014.952370

Prilleltensky, I. (2005). Promoting well-being: Time for a paradigm shift in health and human services. Scandinavian Journal of Public Health, 33(66), 53-60. https://doi. org/10.1080/14034950510033381

Ryff, C.D. (1989). Happiness is everything, or is it? Explorations on the meaning of psychological well-being. Journal of Personality and Social Psychology, 57(6) 1069-1081. https://doi.org/10.1037/0022-3514.57.6.1069

Ryff, C.D., \& Singer, B. (1998). The contours of positive human health. Psychological Inquiry, 9(1), 1-28. https://doi.org/10.1207/s15327965pli0901_1

Shayeghian, Z., Amiri, P., Vahedi-Notash, G., Karimi, M., \& Azizi, F. (2019). Validity and reliability of the Iranian version of the short-form social well-being scale in a reliability of the Iranian version of the short-form social well-being scale in a
general urban population. Iranian Journal of Public Health, 48(8), 1478-1487. https://doi.org/10.18502/ijph.v48i8.2988

South African Department of Health (DOH). (2014, September 19). National Health Act (Act No. 61 of 2003) Regulations relating to research with human participants. Government Gazette No. R. 719. Pretoria: Government Printing Works.

South African Department of Health (DOH). (2015). Ethics in health research Principles, structures and processes. Retrieved from http://www.nhrec.org.za/ docs/Documents/EthicsHealthResearchFinalAused.pdf

Wang, J., \& Wang, X. (2012). Structural equation modeling: Applications using mplus. West Sussex: Wiley.

White, S.C. (2010). Analysing well-being: A framework for development practice. Development in Practice, 20(2), 158-172. https://doi.org/10.1080/ 09614520903564199 
White, S.C. (2017). Relational well-being: Re-centring the politics of happiness, policy and the self. Policy \& Politics, 45(2), 121-136. https://doi.org/10.1332/03055731 7X14866576265970

Wilson, A., Wissing, M.P., \& Schutte, L. (2019). 'We help each other': Relational patterns among older individual in South African samples. Applied Research in Quality of Life, 14, 1373-1392. https://doi.org/10.1007/s11482-018-9657-5

Wilson Fadiji, A., Meiring, L., \& Wissing, M.P. (2019). Understanding well-being in the Ghanaian context: Linkages between lay conceptions of well-being and measures of hedonic and eudaimonic well-being. Applied Research in Quality of Life: The Official Journal of the International Society for Quality-of-Life Studies, 16, 649-677. https://doi.org/10.1007/s11482-019-09777-2
Wissing, M.P. (2014). Meaning and relational well-being in cross-cultural perspectives. Journal of Psychology in Africa, 24(1), iii-vi. https://doi.org/10.1080/14330237.2 014.904092

Wissing, M.P., \& Temane, M. (2013). South Africa's Truth and Reconciliation process as applied Positive Psychology in nation building. In H. Marujo \& L.M. Neto (Eds.), Building positive nations and communities (pp. 149-170). Dordrecht: Springer.

World Health Organization. (2001). World medical association declaration of Helsinki: Ethical principles for medical research involving human subjects. Bulletin of the World Health Organization, 79(4), 373-374. 